\title{
Psicanálise e cinema: aplicação da análise fílmica para a aprendizagem do conceito de inconsciente
}

\author{
Elizabeth Fátima Teodoro \\ Daniela Paula do Couto 1 \\ Mardem Leandro Silva \\ Roberto Lopes Mendonça (1)
}

Universidade do Estado de Minas Gerais, Divinópolis, Minas Gerais, Brasil

\begin{abstract}
Resumo: Partindo da constatação acadêmica da importância do ensino-transmissão da psicanálise na universidade, este artigo objetiva ser uma peça demonstrativa do quanto o aprendizado do conceito psicanalítico - inconsciente pode ser facilitado por meio da linguagem cinematográfica. Para tanto, a investigação teórica e a análise fílmica psicanalítica foram escolhidas como métodos de pesquisa, estes balizados pela psicanálise aplicada. Utilizam-se filmes consagrados pela mídia, que vão desde Psicose, de Alfred Hitchcock, até Alice no país das maravilhas, de Tim Burton, a fim de dispor em movimento a conceituografia psicanalítica que organiza o conceito de inconsciente em Freud e Lacan. Observa-se, assim, que a novidade freudiana consistiu em desatrelar o inconsciente da consciência e elevá-lo ao estatuto de instância psíquica que se expressa por meio de sonhos, atos falhos, chistes e outros. A partir dessa concepção, posteriormente Lacan propõe o inconsciente estruturado como linguagem provendo o fio fundamental dos laços sociais.
\end{abstract}

Palavras-chave: ensino-transmissão, Freud, Lacan, teoria psicanalítica, vinhetas cinematográficas.

\section{Introdução}

Esta investigação tem como pano de fundo a seguinte questão: como potencializar o ensino-transmissão dos conceitos psicanalíticos na universidade, especialmente na graduação em Psicologia? Tal questionamento traz à tona uma discussão que perpassa a história da psicanálise desde seu início, a saber: é possível ensinar psicanálise nas universidades? Pergunta que Freud (1919[1918]/1996) busca responder em seu texto "Sobre o ensino da psicanálise nas universidades", artigo escrito para tratar das reformas na educação médica que, a partir da inclusão da psicanálise no currículo do curso de Medicina em Budapeste, causou certa agitação. Nessa oportunidade, o mestre de Viena tece comentários sobre o tema com o intuito de apresentar uma série de condições essenciais para o ensino e a transmissão da psicanálise na universidade.

Antes, porém, em "Uma dificuldade no caminho da psicanálise", ele esclarece que a dificuldade referente ao ensino psicanalítico fora dos institutos específicos não se deve a uma questão intelectual, ao contrário, trata-se de uma dificuldade afetiva, visto que, "onde falta simpatia, a compreensão não virá facilmente" (Freud, 1917/1996, p. 145). Dessa forma, o médico vienense deixa claro que é preciso disposição afetiva por parte de quem se propõe a

* Endereço para correspondência: elektraliz@yahoo.com.br enveredar pelos liames psicanalíticos, pois a psicanálise vai para além de uma psicopatologia descritiva, ela "empenha-se em cuidadosas e laboriosas investigações, delineia hipóteses e construções científicas" (Freud, 1919[1918]/1996, p. 150) que "contribuiriam muito para moldar uma ligação mais estreita, no sentido de uma universitas literarum, entre a ciência médica e os ramos do saber que se encontram dentro da esfera da filosofia e das artes" (p. 187). A partir da articulação entre esses campos do conhecimento, "a universidade só teria a ganhar com a inclusão, em seu currículo, do ensino da psicanálise" (p. 187).

Nessa linha de raciocínio, as considerações freudianas sobre o ensino-transmissão da psicanálise na universidade nos permitem duas extrações relevantes, a primeira é concernente à singularidade necessária para se tratar da psicanálise em uma instituição de ensino superior, uma vez que é preciso ter ciência da distinção entre ensino (aprender sobre psicanálise) e transmissão (aprender a partir da psicanálise). Enquanto a primeira trabalha com uma disposição cognitiva que aponta para o universal da teoria, a segunda necessita de uma disposição afetiva, pois exige a inclusão da singularidade existente no drama humano e em seus modos de sofrimento psíquico.

Assim, a dificuldade residiria em se apropriar da universalização dos conceitos, mas sem desconsiderar o particular de cada caso. Por essa razão, o mestre de Viena propõe um tripé fundamental para o ensino-transmissão 
da psicanálise na universidade: apreensão dos conceitos psicanalíticos, análise pessoal e experiência prática supervisionada que, a rigor, possibilitariam o desenvolvimento da escuta clínica que, consequentemente, leva a uma prática eficiente do saber psicanalítico.

A segunda extração dos ditos de Freud (1919[1918]/1996) evidencia a importância de utilizar outras formas de saber, como a filosofia e as artes, na formação acadêmica. Naquela ocasião, o médico vienense falava especificamente sobre a formação em Medicina, contudo, pode-se dizer o mesmo a respeito da Psicologia, visto que se trata de um curso que transita entre as áreas das ciências humanas e da saúde que, consequentemente, exige do discente uma visão ampliada da cultura, como afirmam Chaves, Bittar e Gebrim (2015).

Pensando a importância das artes na formação dos psicólogos, Pedro e Pessoa (2015) destacam que essa aproximação produz no sujeito novas percepções sobre si, o outro e o mundo, uma vez que possibilita reelaborações de pensamentos, conhecimentos e sentimentos. Além de permitir a apreensão de elementos centrais que regem o processo de internalização da cultura, movimento que facilita a educação da sensibilidade para aquilo que é próprio do humano e que, em Psicologia, torna-se fundamental, visto que os psicólogos atuam diretamente com o sujeito e sua complexidade. Desse modo, "precisam a todo momento mediar relações, construir espaços de aprendizagem, administrar emoções, compreender o outro, ou seja, precisam ter um repertório amplo sobre os diferentes aspectos da vida e a imprevisibilidade do humano" (p. 5).

Esse repertório amplo constitui o que, em psicanálise, pode ser denominado recurso simbólico. Por simbólico, entende-se "um sistema de representação baseado na linguagem, isto é, em signos e significações que determinam o sujeito à sua revelia" (Roudinesco \& Plon, 1998c, p. 714). Assim que nasce, o indivíduo é inserido em um mundo simbólico, ou seja, em um mundo de linguagem. Por esse viés, afirma-se que "a função do símbolo é ordenar o modo de funcionamento de uma cultura e influenciar o comportamento do indivíduo organizando suas relações [sociais]" (Françóia, 2007, p. 94).

Nesse contexto, as artes surgem como exemplo ilustrativo de um universo balizado pelo simbólico. Entre as variadas formas de artes, o cinema figura como uma das produções da modernidade, que Lou Andreas-Salomé, grande psicanalista amiga de Freud, em 1913, nomeou de a "cinderela das artes" (Rivera, 2011, p. 10), ao sugerir "que a rapidez da sucessão de imagens permitida pela técnica cinematográfica corresponderia mais ou menos às nossas faculdades de representação" (p. 10), constatação que a levou a questionar "sobre o que o futuro do cinema poderia vir a significar para nossa constituição psíquica" (p. 10).

Se podemos dizer que o surgimento dessa arte é recente, datada de 1895 , como a própria psicanálise, a aproximação entre essas duas expressões da cultura é ainda mais atual, precisamente de 1926, momento em que o diretor Georg Pabst inicia as gravações do filme
Segredos de uma alma, que tinha por objetivo inicial popularizar a psicanálise. Freud, porém, opunha-se a essa ideia, justificando que não era possível uma apresentação fidedigna de uma análise, mas terminou aceitando a proposta e o filme foi fundamentado em um caso atendido por Sachs, membro da Associação Internacional de Psicanálise (Rezende \& Weinmann, 2014).

Posteriormente, muitos estudiosos de psicanálise e psicanalistas desenvolveram trabalhos evidenciando a importância da utilização do cinema para a ampliação e a compreensão da teoria psicanalítica. Dentre esses, citamos Sérgio Telles, que, desde 2004, publica uma coleção intitulada $O$ psicanalista vai ao cinema, que já está em seu terceiro volume; Christian Dunker e Ana Lucilia Rodrigues, que publicaram, a partir de 2013, a coleção Cinema e psicanálise, que se encontra em seu oitavo volume; além dos inúmeros departamentos universitários que possuem núcleos de pesquisa e extensão em psicanálise e cinema, como o Núcleo de Pesquisa e Extensão em Psicanálise e Cinema (Nuppcine) da Universidade Federal do Rio Grande do Sul.

Por esse viés, Weinmann (2017) assevera que essas pesquisas podem ser agrupadas esquematicamente nas seguintes tendências:

1) ensaios de compreensão de uma obra à luz da biografia do autor; 2) diagnóstico psicopatológico de personagens; 3) leituras do texto fílmico a fim de detectar sua mensagem inconsciente; e 4) analogias entre a linguagem do cinema e de determinados processos psíquicos, como os sonhos. Em tais abordagens, estamos no domínio da psicanálise aplicada, isto é, a teoria psicanalítica opera como um saber transcendente. Ela ilumina o cinema, mas não se reinventa com ele. (p. 6)

É na perspectiva da quarta tendência que pautamos esta investigação, que objetiva ser uma peça demonstrativa do quanto o aprendizado do conceito psicanalítico inconsciente - pode ser facilitado por meio da linguagem cinematográfica a ponto de ser possível adotar filmes como recurso pedagógico para facilitação do processo ensino-transmissão da psicanálise na universidade, especialmente nos cursos de Psicologia.

\section{Método}

O método se pautou na investigação teórica com enfoque em Sigmund Freud e nas contribuições de Jacques Lacan para o estudo conceitual, sem desconsiderar comentadores como Slavoj Žižek e Luiz Alfredo GarciaRoza, e na análise fílmica psicanalítica de uma prévia seleção de longas-metragens capazes de ilustrar algumas nuances do arcabouço teórico psicanalítico do conceito de inconsciente. No contexto dos discursos freudiano e lacaniano, recorreu-se a uma pesquisa teórica de cunho bibliográfico, que, para Lima e Mioto (2007), 
"implica em um conjunto ordenado de procedimentos de busca por soluções, atento ao objeto de estudo, e que, por isso, não pode ser aleatório" (p. 38). Enquanto, pelo viés cinematográfico, lançamos mão da análise fílmica psicanalítica que visa "escutar a proliferação [do discurso do Outro] nas tramas da linguagem cinematográfica" (Weinmann, 2017, p. 8). Contudo, vale ressaltar que:

A análise fílmica psicanalítica não consiste em um método, mas em uma singular reflexão de cunho metodológico. . . . Ela decorre do anseio do autor, firmemente enraizado na tradição psicanalítica, de tomar as produções da cultura - mais precisamente, seus efeitos subjetivantes - como o que faz contraponto à clínica, isto é, o que permite pensar, de outro ângulo, os problemas que ela coloca. Nesse sentido, o cinema é compreendido como uma alteridade possível à psicanálise; alteridade essa que incita à invenção conceitual. A fim de operar com a diferença encarnada pela linguagem cinematográfica, a análise fílmica psicanalítica toma como interlocutores privilegiados algumas vertentes dos estudos fílmicos, especialmente a semiótica do cinema, proposta por Christian Metz, e a análise fílmica, tal como inaugurada por Raymond Bellour. (Weinmann, 2017, p. 9)

Portanto, esta pesquisa foi balizada pela psicanálise aplicada, metodologia inaugurada por Freud como "aplicação da psicanálise" e nomeada por Mezan (1985) como "psicanálise aplicada", visto que se aplicou o método psicanalítico fora do contexto clínico tradicional, ou seja, utilizou-se o método psicanalítico na pesquisa científica e acadêmica envolvendo outra área do conhecimento.

Os procedimentos realizados no percurso investigativo podem ser descritos da seguinte forma: trabalhou-se com um tema-conceito (inconsciente) associando-o a temas-filmes, ou seja, um conceito foi escolhido por seu valor fundamental e, desse conceito, derivaram-se conceitos auxiliares que foram estudados via textos e dicionários de psicanálise. A partir desse estudo, organizou-se uma constelação conceitual para a qual os filmes serviram de exemplo clínicotemático. Seguiu-se daí a escrita dinâmica de um estudo psicanalítico histórico do conceito de inconsciente por meio de vinhetas cinematográficas.

Para destacar o conceito de inconsciente, foram trabalhados os seguintes textos de Freud: "Uma dificuldade no caminho da psicanálise" (1917/1996), “Algumas considerações para um estudo comparativo das paralisias motoras orgânicas e histéricas" (1893/1996), "Estudos sobre a histeria" (1893-1995/1996), "A interpretação dos sonhos" (1900/1996, 1900-1901/1996), "Conferência XI - A elaboração onírica" (1916/1996), "Os chistes e suas relações com o inconsciente" (1905/1996), "O inconsciente" (1915), "Além do princípio de prazer"
(1920) e "O Eu e o Isso"" (1923). De Lacan, foram utilizados: "Função e campo da fala e da linguagem em psicanálise" (1953/1998), "A instância da letra no inconsciente ou a razão desde Freud" (1957/1998) e O seminário, livro 5: as formações do inconsciente (1957-1958/1999).

Tais textos foram associados aos seguintes filmes: Sonhos (Kurosawa, 1990), Alice no país das maravilhas (Burton, 2010), A origem (Nolan, 2010), O nome da rosa (Annaud, 1986), Psicose (Hitchcock, 1960), A garota do trem (Taylor, 2016), A guerra do fogo (Annaud, 1981), 10.000 a.C. (Emmerich, 2008) e Náufrago (Zemeckis, 2000).

Utilizaram-se ainda os seguintes conceitos auxiliares: histeria, hipnose, sintoma, Outro, sonho, neurótico, trauma sexual infantil, fantasia, aparelho psíquico, pré-consciente, consciente, ato falho, chiste, primeira e segunda tópica, masoquismo, sadismo, Eu, Isso e Supereu, conflitos psíquicos, formações do inconsciente, significante, real, simbólico, imaginário.

\section{Resultados e discussão}

Por se tratar de uma investigação teórica, os resultados e a discussão se pautaram na escrita dinâmica de um estudo psicanalítico histórico do conceito de inconsciente por meio de vinhetas cinematográficas. Partiu-se, pois, de uma breve apresentação do conceito anterior a Freud, no intuito de esclarecer que não se trata de uma invenção do mestre de Viena. Posteriormente, discorreu-se sobre a evolução do conceito em Freud e em Lacan a fim de evidenciar que o desenrolar dos conceitos na trama psíquica é de extrema complexidade e, muitas vezes - senão todas -, difíceis de trabalhar isoladamente, visto que é justamente o entrelaçamento de tais conceitos que constitui a noção de aparelho psíquico ou de sujeito do inconsciente. Destaca-se ainda a noção fundamental de que, em psicanálise, principalmente em Freud e em Lacan, há uma evolução conceitual que nos exige uma localização clara do momento teórico a que pertence para que os textos freudianos e lacanianos não percam a força da novidade que expressam.

\section{Nos primórdios da construção do conceito de inconsciente}

Ao remontar o processo de construção do conceito de inconsciente, cabe uma ressalva importante sobre sua origem: diferentemente do que muitos acreditam e disseminam, não foi forjado por Freud. Tal termo já era utilizado muito antes da fundação da psicanálise. No contexto filosófico, por exemplo, pensadores como Gottfried Wilhelm Leibniz (1646-1716), Friedrich Nietzsche (1844-1900) e Arthur Schopenhauer (17881860) já trabalhavam com essa conceituação. Também no contexto psicológico, Gustav Fechner e Wilhelm Wundt,

1 Na Edição Standard, a tradução é $O$ Ego e o $I d$, porém, neste texto, optou-se por utilizar os termos Eu, Isso e Supereu. 
nos primórdios da psicologia experimental, enfatizaram "o lado sombrio da alma humana [procurando] fazer emergir a face tenebrosa de uma psique imersa nas profundezas do ser" (Roudinesco \& Plon, 1998a, p. 375), pois suas investigações apontavam que havia algo mais que a consciência na psique humana. Entretanto, é com Freud (1915/1996) que o inconsciente se torna uma instância independente da consciência, algo que pode ser revelado por meio de sonhos, lapsos, atos falhos e outras formações, e é justamente essa a novidade freudiana.

Assim, diferentemente das teorias filosóficas e psicológicas que existiam até então, Freud (1915/1996) propõe uma leitura fundamentada em suas descobertas clínicas. Por esse viés, o inconsciente passa a ser uma conjectura capaz de explicar um vasto aspecto da fenomenologia clínica. Nesses termos, o médico vienense pontua que "o ato psíquico é inconsciente e pertence ao sistema Ics" (p. 178), ou seja, trata-se de reconhecer, no inconsciente, uma hipótese explicativa, e é nesse sentido que muitos conferem à Freud a descoberta do inconsciente. Como afirma Garcia-Roza (2009), a "quasetotalidade dos teóricos em psicanálise concordaria com esta afirmação, embora nem todos concordem quanto à significação, à extensão e aos limites daquilo que entendem por inconsciente" (p. 168). Assim, nossa empreitada de tentar responder o que é o inconsciente não se mostra uma tarefa fácil, ideia reforçada por Jorge (2008) ao assegurar que a "questão sobre o que é o inconsciente foi continuamente sustentada por Lacan ... enquanto enigma que exige decifração" (p. 9).

Isso porque, como afirma o próprio Freud (1917/1996), a descoberta do inconsciente inflige o “terceiro golpe sobre o amor próprio do homem" (p. 151). O primeiro deles seria referente ao golpe cosmológico, oriundo da descoberta de Copérnico, que retirou a Terra do centro do universo; o segundo golpe corresponderia ao golpe biológico e surge com a percepção de Darwin de que o homem não é superior aos demais animais, o que significa que ele não está no centro da criação; por fim, o terceiro golpe ele nomeou de golpe psicológico e descentrou o homem de si mesmo.

Desse modo, evidencia-se, em consonância com Garcia-Roza (2009,) que "qualquer que tenha sido, porém, a noção de inconsciente elaborada antes de Freud, o fato é que ela não designava nada de importante ou de decisivo para a compreensão da subjetividade" (p. 170). Portanto nossa investigação do percurso conceitual do inconsciente focará nos desdobramentos que se iniciam com Freud e posteriormente são retomados por Lacan.

\section{O inconsciente à luz da linguagem cinematográfica}

O contato de Freud com as histéricas permitiu que ele observasse que o tipo de sintoma que elas apresentavam não era indicativo de alguma disfunção fisiológica. Sua hipótese era a de que determinada carga afetiva atingia diretamente a representação do órgão ou função que parecia doente. Isso significava que, por exemplo, uma paciente com um braço paralisado teria "seus movimentos liberados tão logo essa quantidade de afeto [fosse] eliminada" (Freud, 1893/1996, p. 214).

É nesse contexto que surgem os primeiros esboços de uma teoria dos processos psíquicos inconscientes. Porém, é em "A interpretação dos sonhos" que Freud (1900/1996) começa a elaborar a teoria que se descortinará em um campo novo do conhecimento e receberá o nome de psicanálise. Por esse viés, o mestre de Viena evidencia que, por meio dos sonhos, era possível ter acesso ao inconsciente, visto que o sonho é constituído de imagens que só podem ser expressas por meio da linguagem. O relato dos sonhos, portanto, possibilitava sua interpretação. Nessa perspectiva, Santiago (2017) propõe que é possível "representar o inconsciente como uma aparelhagem interpretável".

Dessa forma, a importância do estudo dos sonhos está no fato de que ele é apresentado por Freud (1915/1996) como uma das manifestações possíveis do inconsciente. Nessa esteira de pensamento, destacam-se três filmes que oferecem algumas elucidações interessantes sobre as formulações freudianas dos sonhos e seu modo de funcionamento: Sonhos, do diretor Akira Kurosawa (1990), Alice no país das maravilhas, de Tim Burton (2010), baseado na obra homônima de Lewis Carroll, e A origem, de Christopher Nolan (2010).

A primeira película - Sonho - consiste em uma produção japonesa que apresenta uma sequência de oito sonhos, alguns dos quais, inclusive, retratam a infância de Kurosawa. Essas cenas nos parecem ainda mais reais quando o próprio diretor esclarece que o filme materializa alguns dos sonhos que persistiram ao longo de sua vida. Sem nos atermos em nenhum sonho específico, chamanos a atenção o modo pelo qual as imagens se sobrepõem em cada seguimento onírico praticamente destituído de palavras. O que nos permite evidenciar, como formulado por Freud (1900/1996), que os sentidos dos sonhos só são elaborados a posteriori, semelhante ao que vamos fazendo ao longo do filme, com a diferença de que, na interpretação de um sonho, somente o sonhador é capaz de dizer de seu sonho.

Alice no país das maravilhas, o segundo longametragem, narra a história de uma garota inteligente e observadora que se sentia deslocada no contexto em que vivia e, diante do pedido de sua mão em casamento, avista e se coloca a perseguir um coelho branco que a leva para um mundo mágico no qual todos os acontecimentos se mostram diferentes do que ela conhecia até então. Interessa-nos aqui estabelecer uma analogia entre as cenas fílmicas e o que Freud (1900/1996) denominou de conteúdo manifesto e latente dos sonhos que, "devido à censura, se manifesta através de disfarces, alusões e simbolismos ... de maneira que, ao ser trazido à consciência do sonhador, não cause a repulsa e o desconforto excessivos que ocorreriam caso o material 
inconsciente fosse acessado integralmente" (Maliska \& Tavares, 2012, p. 8).

Assim, a partir do dispositivo clínico, entende-se que o conteúdo manifesto corresponderia ao relato do sonho feito pelo próprio sonhador, enquanto o conteúdo latente consistiria nos elementos que precisam ser depurados, decifrados, pois se encontram no inconsciente, visto que foram deturpados pela censura. Desse modo, cenas bizarras e situações grotescas se justificam, principalmente no País das Maravilhas, uma vez que ele pode ser pensado enquanto o que o fundador da psicanálise afirma ser "diferente da cena da vida representacional de vigília" (Freud, 1900/1996, p. 566). Nesse sentido,

se fizermos uma série de comparações entre os pensamentos oníricos e os sonhos manifestos que os substituem, encontraremos toda sorte de coisas para as quais estamos despreparados; por exemplo, que o disparate e o absurdo dos sonhos possuem seu significado. (Freud, 1916/1996, p. 178)

A origem, por sua vez, apresenta a história de Cobb, especialista em invadir e roubar segredos que se encontram no inconsciente das pessoas, especialmente, durante o sono, momento em que a mente está mais vulnerável. A narrativa gira em torno da invasão da mente de um homem, com o intuito de lhe implantar uma memória. Essa operação conta com cinco personagens além do protagonista, cada qual atua em um nível do sonho para tentar convencer a vítima a adentrar mais profundamente em sua psique. Nessa perspectiva, os cinco níveis do sonho propostos no longa-metragem nos permitem uma analogia com a formulação teórica de Freud (1900/1996) de uma representação tópica do aparelho psíquico ${ }^{2}$, a fim de se compreender o funcionamento da primeira tópica (1900-1920) freudiana. Esse modelo dispõe de três instâncias: inconsciente (Ics), pré-consciente (Pcs) e consciente (Cs), e dois sistemas: inconsciente e pré-consciente/consciente, orientado no sentido progressivo-regressivo. O que significa que caminham do inconsciente para o pré-consciente e, posteriormente, para o consciente.

Para Freud (1900/1996), a principal característica dessa tópica é dar um sentido à energia investida a fim de que ela se torne móvel e possa ser descarregada. Essa energia se divide pelos dois sistemas acima mencionados, mas enquanto o sistema inconsciente luta por ficar livre dessa energia, pois o acúmulo dela provoca desprazer, os outros dois sistemas buscam inibir essa descarga, impondo restrições ao primeiro sistema e colocando o aparelho psíquico em movimento, ao buscar repetir a primeira experiência de satisfação.

Outras vinhetas interessantes do filme auxiliam na compreensão dos conteúdos que habitam o inconsciente que,

2 Vale ressaltar que aparelho psíquico diz respeito a um "modelo explicativo que não supõe qualquer sentido denotativo do real" (GarciaRoza, 2009, p. 46). na teoria freudiana, correspondem a representações recalcadas. No longa, Cobb possui representações recalcadas advindas da culpa que sente pela morte de sua esposa, essas memórias invadem seus sonhos constantemente na tentativa de redimir sua culpa. Assim, a partir das vivências oníricas do protagonista e do arcabouço teórico do fundador da psicanálise, percebe-se que os sonhos, além de serem a realização de desejos inconscientes, também funcionam como um modo de manter o equilíbrio psíquico, não permitindo vir ao consciente representações recalcadas.

Posteriormente, Freud (1905/1996) escreve "Os chistes e sua relação com o inconsciente", texto que fundamenta o inconsciente a partir de sua estrutura de linguagem. Para Roudinesco e Plon (1998b), "após A interpretação dos sonhos e a Psicopatologia da vida cotidiana, Os chistes e sua relação com o inconsciente foi a terceira grande obra de Freud dedicada à elaboração de uma nova teoria do inconsciente" (p. 112). Isso porque o mestre de Viena evidenciou que a lógica do inconsciente não está presente somente nos sonhos, como afirmou inicialmente em "A interpretação dos sonhos", mas também na vida cotidiana com atos falhos e chistes. Assim, Freud (1905/1996) verificou que, em muitos casos, o riso se apresentava como efeito do que escapava à consciência.

Essa questão do riso é ilustrada, de forma bem interessante, no filme $O$ nome da rosa, do diretor JeanJacques Annaud (1986), baseado no romance homônimo do autor Umberto Eco. A película narra a história de um mosteiro beneditino no ano de 1327, no norte da Itália, que possuía uma vasta biblioteca de construção labiríntica, de modo que, ao mesmo tempo em que insinuava a verdade do conhecimento que continha, a escondia. Mediante esse jogo de mostra/esconde, verdade/mentira, oculto/ claro, desenrola-se a trama do longa-metragem que gira em torno de algumas mortes de monges aparentemente inexplicáveis que estavam acontecendo no mosteiro.

Em determinado momento, frei Guilherme de Baskerville (Sean Connery) descobre que ocultam na biblioteca muitos livros proibidos devido ao seu conteúdo. Dentre eles, estava a Poética de Aristóteles, que tratava da tragédia (parte a que temos acesso hoje) e da comédia (parte que parece ter se perdido). $O$ filme trata justamente desta parte desaparecida (a comédia), mas citada vagamente pelo próprio filósofo. Nesse ínterim, o riso era considerado por muitos membros do clero um atentado à fé, pois acreditavam que havia algo de demoníaco e pecaminoso no riso. Descobriu-se, posteriormente, que havia uma relação direta entre a leitura do livro proibido e as mortes misteriosas.

Trazemos essa narrativa fílmica por nos permitir realizar uma boa analogia da biblioteca com o aparelho psíquico e seu funcionamento proposto por Freud nos textos anteriormente citados. Assim como o aparelho psíquico freudiano, a biblioteca é estratificada, ela está fora do registro da consciência, ou seja, está fora do que pode ser conscientemente percebido, existem várias salas ligadas por uma escadaria labiríntica que leva o 
sujeito a se perder para se encontrar. Há uma passagem secreta desde a qual há um dentro e um fora, algo que impediria a passagem e que, embora não exerça a força do recalque freudiano, mantém escondida a informação que permanece dentro e, uma vez dentro, há o risco de se perder e não mais conseguir sair.

Junto à construção do conceito de inconsciente, o mestre vienense desenvolveu o conceito de pulsão em obras diferentes. Entretanto foi com os artigos de metapsicologia, especialmente $O$ inconsciente, que Freud (1915/1996) estabeleceu uma profunda inter-relação entre inconsciente e pulsão. Essa inter-relação o levou a verificar que tanto a teoria da primeira tópica quanto o conceito de inconsciente se mostravam insuficientes para explicar o funcionamento do aparelho psíquico, principalmente nos casos em que o sujeito não suportava ser aliviado de seu sintoma, ou seja, casos de masoquismo e/ou sadismo.

Assim, em "Além do princípio do prazer", texto que sinaliza a passagem da primeira tópica para a segunda, Freud (1920/1996) propõe a pulsão de vida e a pulsão de morte, que ultrapassam a questão do princípio de prazer/ desprazer da primeira tópica e, em "O Eu e o Isso", Freud (1923/1996) faz uma revisão no modo de abordagem do aparelho psíquico, originando a segunda tópica ${ }^{3}$ (19201939) com o isso, eu e supereu. Tais instâncias não têm ao mesmo tempo a qualidade de serem conscientes e inconscientes, de forma que o Isso só tem acesso ao mundo externo pelo recurso de formação do Eu. Assim, o eu que, até então, dizia respeito à constituição identificatória do sujeito por meio do afeto estabelecido com os outros, agora se torna também uma instância de regulação da segunda tópica, com função de equilibrar as exigências entre o isso, relacionada à reserva pulsional, na qual reina o princípio de prazer, e do supereu, instância crítica que exerce funções de juiz e censor em relação ao eu.

Para movimentar essa parte do conceito, lançamos mão de Alfred Hitchcock (1960) em Psicose. Filme que retrata a vida de Norman Bates, um rapaz aparentemente tímido e totalmente controlado por sua mãe. Žižek (2006), n'O guia pervertido do cinema ${ }^{4}$, expõe uma analogia interessante e bastante ilustrativa entre a casa, os ambientes nos quais transcorrem as encenações e a teoria da segunda tópica freudiana:

Os eventos se desenvolvem em três níveis: primeiro andar, térreo, porão. Estes três espaços reproduzem os três níveis da subjetividade humana. O térreo é o eu. Norman se comporta ali como um filho normal, o que quer que reste de seu eu normal no comando. Lá em cima está o supereu. O supereu materno, pois

3 É digno de nota que a segunda tópica não exclui a primeira, ao contrário, são complementares, uma vez que os fenômenos psíquicos são descritos a partir de diferentes ângulos. Assim como não se refere a topos, mas sim a qualificações das instâncias (Garcia-Roza, 2009).

4 Trata-se de um documentário dirigido pela inglesa Sophie Fiennes que tem como protagonista o filósofo esloveno Slavoj Žižek, que aborda diversos conceitos psicanalíticos e temas ligados à condição humana a partir de cenas oriundas de grandes clássicos do cinema. a mãe morta é basicamente a figura do supereu. E embaixo, na despensa, está o isso. O reservatório dessas pulsões ilícitas. (Žižek, 2006)

O autor complementa sua análise do filme apresentando uma vinheta que exemplifica com perfeição a dinâmica do aparelho psíquico a partir dessa segunda tópica:

Quando Norman carrega a mãe ou, como se descobrirá, a múmia, o cadáver, o esqueleto da mãe, do primeiro andar ao porão, é como se ele a estivesse deslocando em sua própria mente, como instância psíquica do supereu ao isso. É claro, trata-se da mesma velha lição elaborada por Freud, segundo a qual o supereu e o isso estão intimamente ligados. A mãe reclama primeiramente como figura autoritária. ... E então a mãe imediatamente se torna obscena. . . . O supereu não é uma instância ética, é uma instância obscena que nos bombardeia com ordens impossiveis e que ri de nós quando não conseguimos atender às suas demandas. Quanto mais obedecemos, mais ele nos faz sentir culpados. (Zizek, 2006)

Pensando um supereu que não seja materno, mas ainda assim exerça uma força tamanha sobre o eu que o leva à quase consumição, temos o filme $A$ garota do trem, com direção de Tate Taylor (2016), baseado no romance homônimo de Paula Hawkins. O filme conta a história de Rachel Watson, que, após a frustração de seu casamento e um divórcio conturbado, se vê fantasiando sobre a vida perfeita de um casal para o qual olha todos os dias pela janela do trem que a leva à cidade. Certo dia, a protagonista assiste uma cena estranha entre o casal e passa a investigar a vida deles.

Essa narrativa nos interessa no ponto em que podemos fazer uma analogia da influência do ex-marido sobre Rachel. O que nos leva a pensar que seu ex-marido se tornou o supereu da personagem principal, enfraquecendo seu eu e destruindo qualquer conexão com o isso. Ele alimentava o vício em bebidas alcoólicas e implantava um sentimento de culpa que a paralisava. Como ela acreditava na imagem que seu ex-marido havia montado dela, sua autoestima praticamente não existia, o que tornava seu eu ainda mais frágil.

A ambientação do filme é bem significativa, uma vez que Rachel passa grande parte do tempo em um trem, indo de Ashbury - onde mora - para Londres e vice-versa. Seu olhar avista da janela um mundo que, por vezes, ela anseia, mas do qual não consegue fazer parte. Ela deseja a vida de outra pessoa porque sente não possuir mais sua própria vida. Assim, ela imagina como seria ser a mulher daquele casal que observa todos os dias por alguns míseros segundos enquanto o trem passa em frente à casa do casal. Esse movimento psíquico de Rachel nos permite pensar como as primeiras formulações teóricas sobre a fantasia, em Freud, têm uma representação ficcional que tenta 
escamotear um trauma psíquico que, ao ser recalcado, jaz no inconsciente (Breuer \& Freud, 1893-1895/1996).

A partir desse breve resgate freudiano do conceito de inconsciente, recorremos às palavras de Dunker (2008) para uma possível definição:

o inconsciente é o retorno. Não postulamos aqui uma identificação entre estes dois conceitos, decerto dispares entre si, mas uma noção mais ampla e genérica (o retorno) que condiciona e inclui um conceito central (o inconsciente). O retorno é uma hipótese operativa, não exclusiva nem fundante da psicanálise, o inconsciente é uma hipótese metapsicológica que pretende explicar e organizar as formas do retorno. $O$ retorno pode ser descrito, como fenômeno de reconhecimento, o inconsciente só se apreende por seus derivados. (p. 112, ênfase adicionada)

Já em Lacan, o inconsciente pode ser pensado em dois tempos, como pontua Santiago (2017). No primeiro, há uma releitura freudiana em que a interpretação se refere a um fenômeno de inconsciente que aponta para o indizível. Nesse sentido, a interpretação assume o status de decifração, em que "o analista, precisamente, porque é Outro, deve estar à altura de dizer o indizível do analisante. No segundo, ele acrescenta a sexualidade como um elemento que embaralha as cartas de sua concepção anterior do inconsciente". Assim, a interpretação passa a decifrar os significantes.

No que concerne à releitura realizada por Lacan da obra freudiana, verifica-se, no texto "Função e campo da fala e da linguagem em psicanálise", a seguinte formulação: "o inconsciente é a parte do discurso concreto, como transindividual, que falta à disposição do sujeito para restabelecer a continuidade de seu discurso consciente" (Lacan, 1953/1998, p. 260). Assim, Lacan redirecionou a psicanálise para o campo da linguagem se utilizando e subvertendo as teorias de linguistas como Ferdinand de Saussure e Roman Jakobson. E em "A instância da letra no inconsciente ou a razão desde Freud", Lacan (1957/1998) demonstrou que o inconsciente é estruturado como linguagem.

Levando em consideração que a psicanálise opera fundamentalmente por meio da fala do analisando, Lacan (1957-1958/1999), n'O seminário, livro 5: as formações do inconsciente, estabelece a relação entre as formações do inconsciente e a linguagem, uma vez que é por ela que tais formações se manifestam. Desse modo, a teoria da cadeia de significantes se tornou mais consistente, em que os significantes deslizam sem cessar e insistem em interferir no discurso, seja como dito que escapa à intenção do dizer, seja como elaboração onírica, fazendo que o sonho se apresente para seu autor como enigma a ser decifrado. Utilizando-se da função simbólica de Lévi-Strauss, em Estruturas elementares de parentesco, o analista francês propõe o inconsciente como função simbólica, sendo a linguagem o elemento essencial da constituição simbólica. Segundo Garcia-Roza (2009), "só há o social porque há o simbólico" (p. 175), isso porque é o simbólico que possibilita a troca no interior dos grupos sociais (Lacan, 1953/1998).

Nessa esteira de pensamento, filmes como A guerra do fogo, de Jean-Jacques Annaud (1981), que retrata uma época há 80 mil anos a.C., período paleolítico, e o confronto de três tribos de espécies diferentes (homo neanderthalensis, homo erectus e homo sapiens) que buscavam o domínio do fogo; e 10.000 a.C., do diretor Roland Emmerich (2008), que mostra o encontro de uma tribo primitiva com uma civilização perdida; evidenciam as diferenças culturais, os desencontros e encontros simbólicos de cada povo. Pode-se compreender melhor essa questão a partir do que aponta Dunker (2008): "Ganha-se assim uma concepção de inconsciente que não é reduzida nem à sua função de defesa nem à sua substância formada por complexos. Todavia esta noção depende agora das trocas sociais" (p. 113).

Nesse sentido, o inconsciente se apresenta como o discurso do Outro, lugar de um significante puro no qual se marca a divisão (clivagem) do sujeito. Chaves (2002) nos esclarece que esse Outro não se refere ao outro especular, semelhante, mas se trata do "Outro enquanto alteridade absoluta, ou seja, o sujeito é agora constituído pelo Outro (Autre), representante da linguagem. O sujeito é, então, efeito do significante, pois está submetido à sua lei” (p. 69). Assim, na acepção lacaniana, o inconsciente é a soma dos efeitos da fala sobre um sujeito, naquele nível em que o sujeito se constitui dos efeitos do significante.

Em Náufrago, dirigido por Robert Zemeckis (2000), também temos a percepção da importância do outro/Outro. O filme apresenta a história de Chuck Noland, um executivo obcecado pela excelência do desempenho e controle total de suas ações, que, devido a um acidente, se vê isolado em uma ilha após um naufrágio. Com o passar o tempo e mediante o insustentável da solidão, o protagonista inventa um interlocutor chamado Wilson a partir de uma bola de vôlei para lhe fazer companhia. Trazemos essa vinheta cinematográfica com o intuito de evidenciar o quanto o outro/Outro continua sendo necessário para devolver ao personagem sua existência.

Nesses termos, percebe-se com Dunker (2008) que a "noção de inconsciente estruturado como uma linguagem é deslocada, ... para uma vigorosa teoria do sujeito" (p. 117). Assim, a partir da investigação centrada no imaginário até seu retorno a Freud, Lacan (1949/1998) propõe abordar a hipótese do inconsciente freudiano pelo recurso de considerar a existência do sujeito do inconsciente, sujeito esse que se manifesta por um lapso, um esquecimento, um sonho, um chiste, um sintoma, enfim, uma formação do inconsciente.

\section{Considerações finais}

Este estudo nos possibilitou demonstrar como o ensino-transmissão de um conceito psicanalítico 
fundamental como o inconsciente pode ser facilitado por meio da utilização do universo cinematográfico. Isso porque a linguagem fílmica se constitui basicamente de representações de imagens que deslizam signos, significantes e significações, podendo ser pensados enquanto analogia do funcionamento psíquico desenvolvido por Freud e formalizado por Lacan. É nesse contexto que Droguett (2004) assegura que

O cinema como linguagem organiza uma narrativa e cria sentimentos, assim as imagens falam através do olhar, da câmera e do espectador. Olhar a imagemé ser a imagem: nisto consiste a subversão científica da psicanálise, que marca a prática interdisciplinar da ciência do inconsciente e da ciência da imagem. (p. 256)

Quanto ao conceito de inconsciente, assinalamos que sua origem é anterior ao nascimento da psicanálise, visto que ele já se constituía enquanto objeto conceitual de reflexão tanto para a filosofia quanto para os primórdios da psicologia. A novidade freudiana, pois, consistiu em desatrelar o inconsciente da consciência e elevá-lo ao estatuto de instância psíquica. A partir de então, temos a construção da organização psíquica à revelia de nossas ações conscientes. Não sem razão, os sonhos, assim como os lapsos e chistes são considerados tanto pelo médico vienense quanto para o psicanalista francês como formações do inconsciente.

Contudo é interessante perceber que o arcabouço conceitual psicanalítico não pode ser tratado de maneira estanque, uma vez que a construção teórica se baseia na prática clínica e vice-versa, o que fornece a essa conceituografia movimento constante. Assim, destacamos que, se Freud inicia suas formulações considerando o inconsciente semelhante aos sonhos, Lacan termina por evidenciá-lo enquanto estruturado como uma linguagem, de natureza simbólica e, portanto, essencial nas construções dos laços sociais.

\section{Agradecimentos}

Ao Fundo de Amparo à Pesquisa do Estado de Minas Gerais (Fapemig) pelo financiamento da pesquisa "A arte imita a vida: articulações entre Psicanálise e cinema", da qual se originou este artigo.

\title{
Psychoanalysis and cinema: application of film analysis for learning the concept of the unconscious
}

\begin{abstract}
Based on the academic observation of the importance of teaching-transmitting psychoanalysis at the university, this article aims to show how much the learning of the psychoanalytic concept - unconscious - can be facilitated through the cinematographic language. For such purpose, theoretical research and psychoanalytic film analysis were chosen as research methods, these guided by applied psychoanalysis. Films consecrated by the media are used, ranging from Alfred Hitchcock's Psychosis to Tim Burton's Alice in wonderland to set in motion the psychoanalytical conceptualization that organizes the concept of the unconscious in Freud and Lacan. It is observed, therefore, that the Freudian novelty consisted of uncoupling the unconscious from consciousness and elevating it to the status of a psychiatric instance that is expressed through dreams, flawed acts, jokes and others. From this conception, Lacan later proposes the unconscious structured as a language providing the fundamental thread of social ties.
\end{abstract}

Keywords: teaching-transmission, Freud, Lacan, psychoanalytic theory, cinematographic vignettes.

\section{Psychanalyse et cinéma : application de l'analyse filmique pour l'apprentissage du concept d'inconscient}

Résumé : Basé sur l'importance de l'enseignement-transmission de la psychanalyse à l'université, cet article s'avère être une démonstration de la manière dont l'apprentissage du concept psychanalytique - l'inconscient - peut être facilité par le langage cinématographique. Pour ce faire, la recherche théorique et l'analyse psychanalytiques de films ont été choisies comme méthodes de recherche, celles-ci fondées sur la psychanalyse appliquée. Nous utilisons des films consacrés par les médias: de Psychose d'Alfred Hitchcock, à Alice au pays des merveilles, de Tim Burton, afin de mettre en mouvement la conceptualisation psychanalytique qui organise le concept d'inconscient chez Freud et Lacan. On constate ainsi que la nouveauté freudienne a consisté à découpler l'inconscient de la conscience et à l'élever au rang d'instance psychique qui s'exprime à travers les rêves, les actes manqués, les mots d'esprit et autres. A partir de cette conception, Lacan propose plus tard l'inconscient structuré comme le langage fournissant le fil conducteur du lien social.

Mots-clés : enseignement-transmission, Freud, Lacan, théorie psychanalytique, vignettes cinématographiques. 


\section{Psicoanálisis y cine: aplicación del análisis cinematográfico para aprender el concepto de inconsciente}

Resumen: A partir de la observación académica de la importancia de la enseñanza-transmisión del psicoanálisis en la universidad, este artículo pretende ser una demostración de cuánto se puede facilitar el aprendizaje del concepto psicoanalítico inconsciente por medio del lenguaje cinematográfico. Para ello, se eligieron como métodos de investigación la investigación teórica y el análisis cinematográfico psicoanalítico, guiados por el psicoanálisis aplicado. Se utilizan películas consagradas por los medios de comunicación, como Psicosis, de Alfred Hitchcock, y Alicia en el país de las maravillas, de Tim Burton, para poner en discusión la conceptualización psicoanalítica que organiza el concepto de inconsciente en Freud y en Lacan. Se observa, por tanto, que la novedad freudiana consistió en desacoplar el inconsciente de la conciencia y elevarlo a la categoría de instancia psíquica que se expresa mediante sueños, actos fallidos, chistes y otros. A partir de esta concepción, Lacan propone posteriormente el inconsciente estructurado como un lenguaje que proporciona el hilo fundamental de los lazos sociales.

Palabras clave: enseñanza-transmisión, Freud, Lacan, teoría psicoanalítica, viñetas cinematográficas.

\section{Referências}

Annaud, J.-J. (Diretor). (1981). A guerra do fogo [Filme]. França, Estados Unidos e Canadá: Lume Filmes.

Annaud, J.-J. (Diretor). (1986). O nome da rosa [Filme]. Roma: Cristaldifilm.

Breuer, J., \& Freud, S. (1996). Estudos sobre a histeria. In Edição standard brasileira das obras psicológicas completas de Sigmund Freud (J. Salomão, Trad., Vol. 2, pp. 13-339). Rio de Janeiro, RJ: Imago. (Trabalho original publicado em 1893-1895)

Burton, T. (Diretor). (2010). Alice no país das maravilhas [Filme]. Los Angeles: Walt Disney Pictures.

Chaves, J. C., Bittar, M., \& Gebrim, V. S. (2015). A relação entre indivíduo, sociedade e cultura e suas interfaces com a psicologia e a educação. In J. C. Chaves, M. Bittar, \& V. S. Gebrim (Orgs.), Escritos de psicologia, educação e cultura (Vol. 2, pp. 9-26). Campinas, SP: Mercado de Letras.

Chaves, W. C. (2002). A noção lacaniana da subversão do sujeito. Psicologia, Ciência e Profissão, 22(4), 68-73. doi: 10.1590/S1414-98932002000400008

Droguett, J. (2004). Sonhar de olhos abertos. São Paulo, SP: Arte e Ciência.

Dunker, C. I. L. (2008). Um retorno a Freud. In N. Leite \& F. Trocoli (Orgs.), Um retorno a Freud (pp. 107-122). Campinas, SP: Mercado das Letras.

Emmerich, R. (Diretor). (2008). 10.000 a. C. [Filme]. Burbank: Warner Bros Entertainment.

Françóia, C. R. (2007). O simbólico e a clínica psicanalítica: O início da teoria lacaniana. Revista AdVerbum, 2(1), 87-101.

Freud, S. (1996). Algumas considerações para um estudo comparativo das paralisias motoras orgânicas e histéricas. Edição standard brasileira das obras psicológicas completas de Sigmund Freud (J. Salomão, Trad., Vol. 1, pp. 203-220). Rio de Janeiro, RJ: Imago. (Trabalho original publicado em 1893)

Freud, S. (1976). Sobre o ensino da Psicanálise nas universidades. In Edição Standard Brasileira das Obras Psicológicas Completas de Sigmund Freud (J. Salomão, Trad., Vol. 17, pp. 183-187). Rio de Janeiro, RJ: Imago. (Trabalho original publicado em 1919[1918])
Freud, S. (1996). A interpretação dos sonhos (I). In Edição standard brasileira das obras psicológicas completas de Sigmund Freud (J. Salomão, Trad., Vol. 4). Rio de Janeiro, RJ: Imago. (Trabalho original publicado em 1900)

Freud, S. (1996). A interpretação dos sonhos (II) e Sobre os sonhos. In Edição standard brasileira das obras psicológicas completas de Sigmund Freud (J. Salomão, Trad., Vol. 5). Rio de Janeiro, RJ: Imago. (Trabalho original publicado em 1900-1901)

Freud, S. (1996). Os chistes e sua relação com o inconsciente. In Edição standard brasileira das obras psicológicas completas de Sigmund Freud (J. Salomão, Trad., Vol. 8, pp. 11-233). Rio de Janeiro, RJ: Imago. (Trabalho original publicado em 1905)

Freud, S. (1996). O inconsciente. Edição standard brasileira das obras psicológicas completas de Sigmund Freud (J. Salomão, Trad., Vol. 14, pp. 165-222). Rio de Janeiro, RJ: Imago. (Trabalho original publicado em 1915)

Freud, S. (1996). Conferência XI - A elaboração onírica. In Edição standard brasileira das obras psicológicas completas de Sigmund Freud (J. Salomão, Trad., Vol. 15, pp. 171-184). Rio de Janeiro, RJ: Imago. (Trabalho original publicado em 1916)

Freud, S. (1996). Uma dificuldade no caminho da psicanálise. In Edição standard brasileira das obras psicológicas completas de Sigmund Freud (J. Salomão, Trad., Vol. 17, pp. 143-153). Rio de Janeiro, RJ: Imago. (Trabalho original publicado em 1917)

Freud, S. (1996). Além do princípio de prazer. In Edição standard brasileira das obras psicológicas completas de Sigmund Freud (J. Salomão, Trad., Vol. 18, pp. 13-72). Rio de Janeiro, RJ: Imago. (Trabalho original publicado em 1920)

Freud, S. (1996). O Eu e o Id. In Edição standard brasileira das obras psicológicas completas de Sigmund Freud (J. Salomão, Trad., Vol. 19, pp. 15-82). Rio de Janeiro, RJ: Imago. (Trabalho original publicado em 1923)

Garcia-Roza, L. A. (2008). A interpretação do sonho, 1900 (8a ed., Vol. 2). Rio de Janeiro, RJ: Zahar. 
Garcia-Roza, L. A. (2009). Freud e o inconsciente (24a ed.). Rio de Janeiro, RJ: Zahar.

Hitchcock, A. (Diretor). (1960). Psicose [Filme]. Orlando: Universal Studios.

Jorge, M. A. C. (2008). Fundamentos da psicanálise de Freud a Lacan: As bases conceituais. (5a ed., Vol. 1). Rio de Janeiro, RJ: Zahar.

Kurosawa, A. (Diretor). (1990). Sonhos [Filme]. Tokyo: Warner Bros Entertainment.

Lacan, J. (1998). O estádio do espelho como formador da função do eu tal como nos é revelada na experiência psicanalítica. In Escritos (pp. 96-103). Rio de Janeiro, RJ: Zahar. (Trabalho original publicado em 1949)

Lacan, J. (1998). Função e campo da fala e da linguagem em psicanálise. In Escritos (pp. 238-324). Rio de Janeiro, RJ: Zahar. (Trabalho original publicado em 1953)

Lacan, J. (1998). A instância da letra no inconsciente ou a razão desde Freud. In Escritos (pp. 496-536). Rio de Janeiro, RJ: Zahar. (Trabalho original publicado em 1957)

Lacan, J. (1999). O seminário, livro 5: as formações do inconsciente, 1957-1958. Rio de Janeiro, RJ: Zahar.

Lacan, J. (2008). O seminário, livro 11: os quatro conceitos fundamentais da psicanálise, 1964. Rio de Janeiro, RJ: Zahar.

Lima, T. C. S., \& Mioto, R. C. T. (2007). Procedimentos metodológicos na construção do conhecimento científico: a pesquisa bibliográfica. Revista Katálysis, 10(spe), 3745. doi: 10.1590/S141449802007000300004

Maliska, M., \& Tavares, R. (2012). O conceito psicanalítico de inconsciente na obra Alice no país das maravilhas. In Anais do IV Simpósio sobre Formação de Professores-SIMFOP. Universidade do Sul de Santa Catarina, Campus de Tubarão, Tubarão, SC. Recuperado de https://bit.ly/2RKiIR9

Mezan, R. (1985). Freud, pensador da cultura. São Paulo, SP: Brasiliense.

Nolan, C. (2010). A origem [filme]. Burbank: Warner Bros Entertainment.
Pedro, L. G., \& Pessoa, C. T. (2015). A arte na formação profissional do psicólogo e do professor: possibilidades e reflexões. In VIII Encontro de educação e III Congresso Trabalho docente e processos educativos. Universidade de Uberaba, Uberaba, MG. Recuperado de https://bit. ly/3oNYyBS

Rezende, T., \& Weinmann, A. (2014). O(s) tempo(s) na psicanálise e no cinema: o sentido baseado no só-depois. Trivium - Estudos Interdisciplinares, 6(1), 68-81.

Rivera, T. (2011). Cinema, imagem e psicanálise. Rio de Janeiro, RJ: Zahar.

Roudinesco, E., \& Plon, M. (1998a). Inconsciente. In E. Roudinesco \& M. Plon, Dicionário de psicanálise (pp. 374-378). Rio de Janeiro, RJ: Zahar.

Roudinesco, E., \& Plon, M. (1998b). Os chistes e sua relação com o inconsciente. In E. Roudinesco \& M. Plon, Dicionário de psicanálise (pp. 111-114). Rio de Janeiro, RJ: Zahar.

Roudinesco, E., \& Plon, M. (1998c). Simbólico. In E. Roudinesco \& M. Plon, Dicionário de psicanálise (pp. 714-715). Rio de Janeiro, RJ: Zahar.

Santiago, J. (2017). A realidade do inconsciente é sexual. Recuperado de https://bit.ly/3wyt6dG

Taylor, T. (Diretor). (2016). A garota do trem [Filme]. Glendale: DreamWorks.

Weinmann, A. O. (2017). Sobre a análise fílmica psicanalítica. Revista Subjetividades, 17(1), 1-11.

Zemeckis, R. (Diretor). (2000). Náufrago [Filme]. Los Angeles: 20th Century Fox.

Žižek, S. (Diretor). (2006). O guia pervertido do cinema [Documentário]. Ipswich: Sophie Fiennes.

Recebido: 30/07/2018

Revisado: 07/09/2020

Aprovado: 08/05/2021 